\title{
Spray forming of a titanium alloy by low pressure plasma spraying; plasma spray coatings of Ti-6Al-4V
}

\author{
Keiji SONOYA and Tsukasa WAKABAYASHI \\ Ishikawajima-Harima Heavy Industries Co., Ltd., 1, Shin-Nakahara-Cho, Isogo-Ku, Yokohama \\ 235-8501, Japan \\ TEL:x81-45-759-2196 FAX:x81-45-759-2125 \\ (Received 27, September 2001 Accepted 7, December 2001
}

\begin{abstract}
Various properties of plasma sprayed coatings of a titanium alloy are assessed for obtaining optimum spray forming conditions of the alloy. The results obtained indicate that a low-pressure plasma spraying is a potential method for forming plasma sprayed parts of the titanium alloy.
\end{abstract}

Keywords: atmospheric pressure plasma spraying (APS), vacuum plasma spraying (VPS), spray forming, Ti-6Al-4V alloy, tensile strength

\section{INTRODUCTION}

The titanium alloy of Ti-6Al-4V has been utilized widely in many applications including those in power generating steam turbines because the alloy possesses such superior properties as relatively high melting point, high specific strength (a ratio of strength/density), and high corrosion resistance. However, the machinability of the alloy is relatively poor, and thus, machining of the alloy is expensive with longer machining times.

Thus, a spray forming method of the alloy for manufacturing alloy parts directly from the alloy powder is proposed for solving the problem mentioned above. ${ }^{1}$ In the present study, spray formed coatings of the alloy are prepared by an atmospheric plasma spraying method (APS) and by a vacuum plasma spraying method (VPS), and various properties of these coatings are assessed for obtaining optimum spraying conditions to form sprayed coatings of the alloy.

\section{EXPERIMENTS}

\section{II-A. Spraying methods}

Various properties of the plasma sprayed coatings that are formed by APS and VPS on substrates of SUS304 stainless steel are assessed. The spraying conditions evaluated are the spraying current and the working gas pressure for the APS processing, and the gas pressure inside the spraying chamber, plasma current, and the distance between the spraying gun and a substrate plate for the VPS processing.

\section{II-B. Quality of coatings}

Microstructure observations and micro hardness measurements are conducted on cross sections of the deposited coatings for both the APS and VPS coatings. The coatings are subjected to X-ray diffraction analysis for identifying phases present and compositions of the coatings. The sprayed coatings after being removed from respective substrates are mechanically tested by an Amsler type tensile test machine.

\section{EXPERIMENTAL RESULTS}

\section{III-A. Porosity measurements}

The porosity of the APS deposited coatings are shown in Fig. 1 with respect to the plasma current of $600 \mathrm{~A}, 700 \mathrm{~A}$, and $800 \mathrm{~A}$, and to the $\mathrm{Ar}$ gas pressure at the plasma gun of $0.34 \mathrm{MPa}, 0.48 \mathrm{MPa}$, and $0.62 \mathrm{MPa}$. The porosity increases from $5 \%$ to $10 \%$ with increasing the gas pressure from 0.34 , to 0.48 and $0.62 \mathrm{MPa}$ at the constant current of $600 \mathrm{~A}$. 
This trend of inducing higher porosity at higher gas pressure is true for the different current levels. The lowest porosity recorded is about $2 \%$ when the spraying condition of $700 \mathrm{~A}$, and the gas pressure of $0.34 \mathrm{MPa}$ is employed.

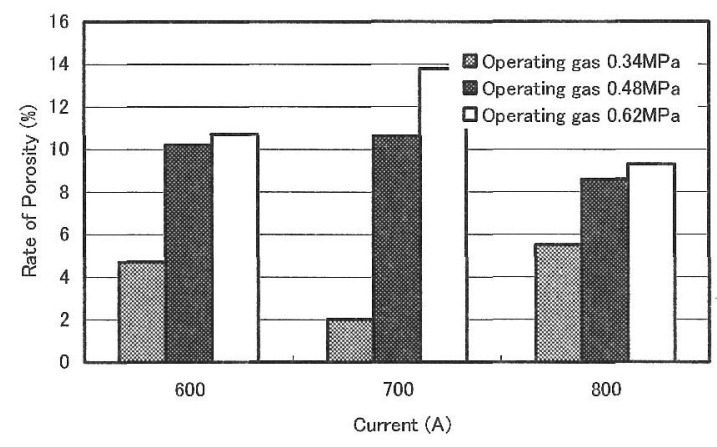

Fig. 1. Relationship between coating porosity and plasma current of APS coatings of Ti-6Al-4V at spray distance of $80 \mathrm{~mm}$ and plasma gas (Ar) pressure of $0.34 \mathrm{MPa}$, secondary gas $(\mathrm{He})$ pressure of $0.34 \mathrm{MPa}$.

The porosity existing in the VPS coatings is shown in Fig. 2 with respect to the distance between the spraying gun and the substrate plate of $150 \mathrm{~mm}$. $200 \mathrm{~mm}$, or $300 \mathrm{~mm}$. The spraying conditions are that the current is $800 \mathrm{~A}$, the chamber pressure is 10 $\mathrm{kPa}$, and the spray gun gas pressure is $0.34 \mathrm{MPa}$. The porosity at the distance of $150 \mathrm{~mm}$ is $3.4 \%$, being the same for the distance of $200 \mathrm{~mm}$. However, it is reduced to $1.1 \%$ when the distance is increased to $300 \mathrm{~mm}$ as shown in Fig. 3 .

\section{III-B. Micro hardness measurement}

The micro hardness of the APS coatings tends to decrease with increasing the gas pressure at the spray current of $600 \mathrm{~A}$, and $700 \mathrm{~A}$. The lowest coating hardness, HV 600, is obtained when the current is $800 \mathrm{~A}$, and gas pressure is $0.48 \mathrm{MPa}$.

The micro hardness of the VPS coatings deposited at the distance of $200 \mathrm{~mm}$ is as high as HV 590, although the hardness is as low as HV 460 at the distance of $300 \mathrm{~mm}$.

\section{III-C. X-ray diffraction results}

X-ray diffraction patterns are shown in Fig. 4 for the raw alloy powder of $\mathrm{Ti}-6 \mathrm{Al}-4 \mathrm{~V}$, the APS coatings and the VPS coatings. The APS patterns

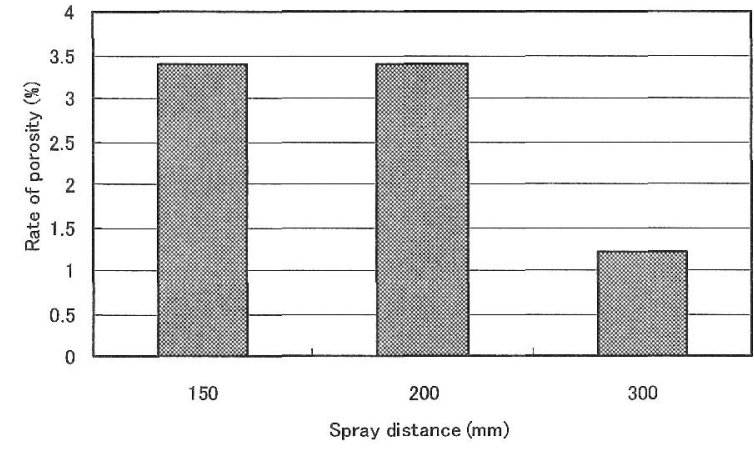

Fig. 2. Relationship between coating porosity and coating distance of VPS coatings of Ti-6Al-4V with plasma current of $800 \mathrm{~A}$, vacuum of $10 \mathrm{kPa}$, gas $(\mathrm{Ar}+5 \% \mathrm{He})$ pressure of $0.34 \mathrm{MPa}$, and secondary gas $(\mathrm{He})$ pressure of $0.34 \mathrm{MPa}$.

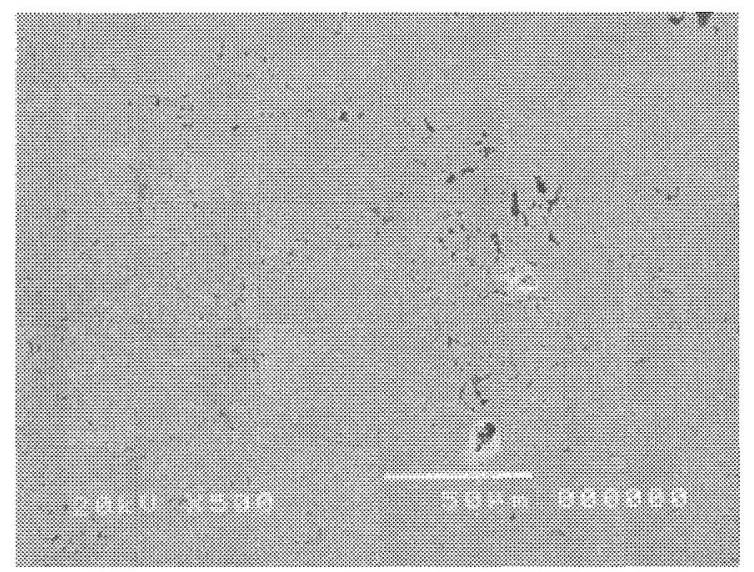

Fig. 3. Microphotograph of VPS coatings of $1.1 \%$ porosity.

contain the diffraction lines from the $\mathrm{TiO}_{2}$ phase at the diffraction angles $(2 \theta)$ of 37.5 and 43.5 degrees of the $\mathrm{Cu}-\mathrm{k} \alpha$ radiation. These diffraction peaks are not detected in the diffraction patterns of the alloy powder specimen. Furthermore, the diffraction patterns of the metallic matrices from the APS coatings show a small degree of line broadening. The diffraction patterns of the VPS coatings are almost identical to that of the alloy powder.

The chemical composition of the VPS coatings is confirmed to be very similar to that of the alloy powder than that of the APS coatings. This is induced by the high chemical reactivity of the titanium alloy in air such as to form the titanium oxide phase during the APS deposition. 


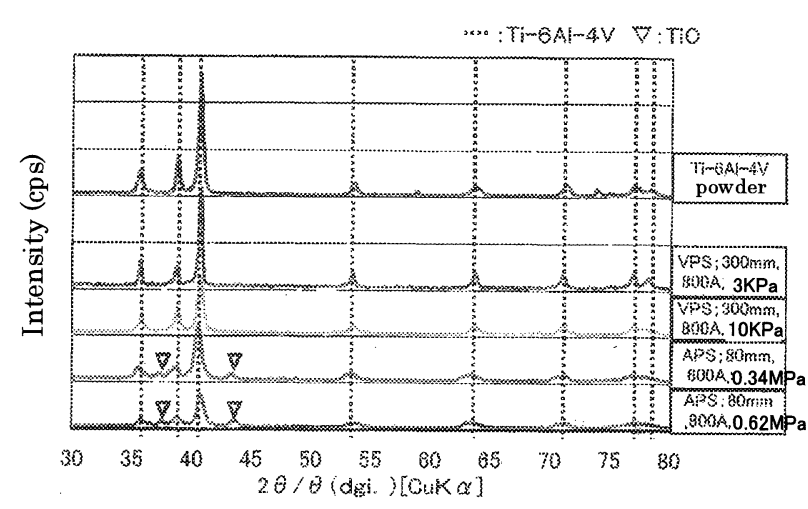

Fig. 4. X-ray diffraction results of Ti-6Al-4V, and plasma sprayed coatings.

\section{III-D. Tensile test results}

The tensile test results are shown in Fig. 5 for the APS films in terms of the plasma current of $600 \mathrm{~A}$, $700 \mathrm{~A}$, and $800 \mathrm{~A}$. The maximum tensile strength is $39 \mathrm{MPa}$, and the lowest value is $24 \mathrm{MPa}$ with the mean value of $33 \mathrm{MPa}$. These values are very much lower than the values being anticipated. The reason for the unexpectedly low strength of the APS films is caused that extremely reduced bonding strength exists between the coated layers by forming appreciable amounts of oxide and nitride phases on the deposited grains. This is revealed by the characteristics of the APS coatings being harder in the hardness measurements and containing the oxide phase in the X-ray diffraction studies.

The tensile test results of the VPS films are shown in Fig. 6 for the coatings deposited under the conditions of the plasma current of $600 \mathrm{~A}$ and $800 \mathrm{~A}$, and the vacuum of 3,10 , and $15 \mathrm{kPa}$. The tensile strength of the VPS films deposited under the vacuum of $3 \mathrm{kPa}$ is about $400 \mathrm{MPa}$ for the plasma current of $600 \mathrm{~A}$ and $800 \mathrm{~A}$. The strength of the film that is deposited at $800 \mathrm{~A}$ is higher than that deposited at the current of $600 \mathrm{~A}$ under the vacuum of $10 \mathrm{kPa}$ and $15 \mathrm{kPa}$. The film deposited at the vacuum of $10 \mathrm{kPa}$ and the current of 800 A shows the highest tensile strength of $850 \mathrm{MPa}$. The reason for the high strength is believed to be induced by slight formation of the oxide phase during the deposition based on the fact that the deposited coating under the condition is turned to blue color on the specimen surface.

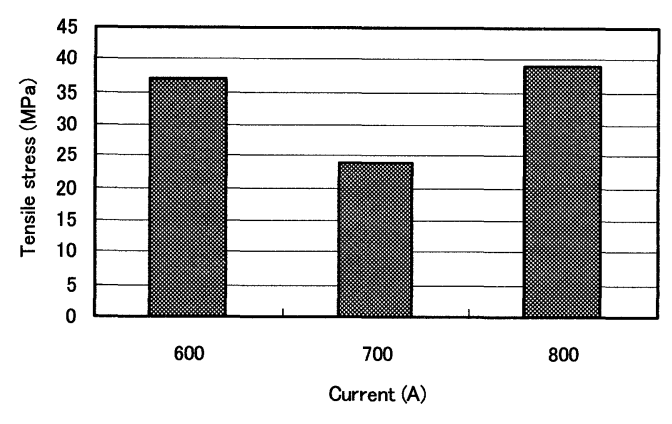

Fig. 5. Tensile strength of APS coatings at spray distance of $80 \mathrm{~mm}$ and plasma gas (Ar) pressure of $0.34 \mathrm{MPa}$, secondary gas $(\mathrm{He})$ pressure of 0.34 $\mathrm{MPa}$.

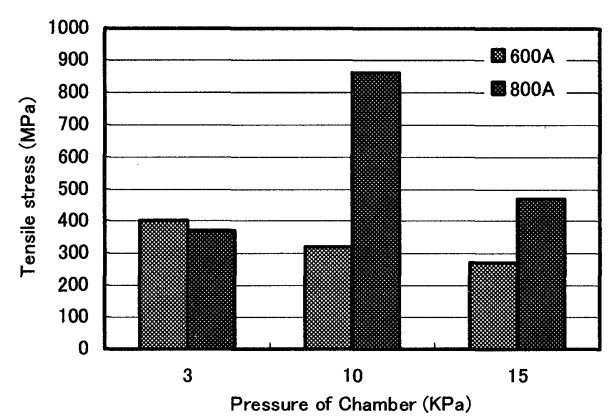

Fig. 6. Tensile strength of VPS coatings at spray distance of $300 \mathrm{~mm}$ and plasma gas $(\mathrm{Ar}+5 \% \mathrm{He})$ pressure of $0.34 \mathrm{kPa}$, secondary gas $(\mathrm{He})$ pressure of $0.34 \mathrm{Mpa}$.

\section{CONCLUSIONS}

Atmospheric plasma sprayed (APS) coatings and vacuum plasma sprayed (VPS) coatings of the Ti-6Al-4V alloy are assessed for developing an optimum spray forming condition of the alloy. The results obtained are summarized as listed below.

(1) The VPS coating method is capable in depositing the titanium alloy coatings of much lower porosity than that of the APS coating method.

(2) The micro hardness of the APS coatings is about HV 600, whereas that of the VPS coating is about HV 460 at most.

(3) The X-ray diffraction data show that the APS coatings contain an oxide phase $\left(\mathrm{TiO}_{2}\right)$, and that the 
VPS coatings have the identical chemical composition to that of the alloy powder of Ti-6Al-4V.

(4) The tensile strength of the APS films is as low as $39 \mathrm{MPa}$, whereas, that of the VPS coatings is 450 $\mathrm{MPa}$ on average.

\section{ACKNOWLEDEMENT}

This study was performed through special
Coordination Funds of the Science and Technology Agency of the Japanese Government.

\section{REFERENCE}

1 T. Mckenie, Proceedings of the 1st International Conference of Thermal Spray, Montreal, 2000, Edited by Christopher C. Bernt, pp. 1105-1116. )

Presented at the $5^{\text {th }}$ International Conference on ECOMATERIALS Oct. 2-4, 2001, Honolulu, Hawaii 